\title{
HIGH VERSATILITY OF NIOBIUM ALLOYED AHSS
}

\begin{abstract}
The effect of processing parameters on the final microstructure and properties of advanced high strength $\mathrm{CMnSiNb}$ steel was investigated. Several processing strategies with various numbers of deformation steps and various cooling schedules were carried out, namely heat treatment without deformation, conventional quenching and TRIP steel processing with bainitic hold or continuous cooling. Obtained multiphase microstructures consisted of the mixture of ferrite, bainite, retained austenite and M-A constituent. They possessed ultimate tensile strength in the range of 780-970 MPa with high ductility $A_{5 \mathrm{~mm}}$ above $30 \%$. Volume fraction of retained austenite was for all the samples around $13 \%$. The only exception was reference quenched sample with the highest strength $1186 \mathrm{MPa}$, lowest ductility $A_{5 \mathrm{~mm}}=20 \%$ and only $4 \%$ of retained austenite.
\end{abstract}

Keywords: TRIP steel, niobium, heat treatment, thermo-mechanical treatment

\section{Introduction}

With increasing concerns for vehicles safety, fuel consumption and carbon footprint, the automotive industry has been increasingly demanding materials, which would maintain good formability while improving tensile strength. The need to decrease the weight of the vehicles has prompted several decades of research and development of new grades of high strength steels. Several grades of advanced high strength steels have been based on the presence of strictly controlled amount and morphology of retained austenite. The first one were TRIP (transformation induced plasticity) steels. They possess high strength, good ductility, formability, and high ability to absorb impact energy. These properties results from their complex microstructure consisting of ferrite, bainite and retained austenite. Stabilization of retained austenite to room temperature is achieved by a special heat or thermo-mechanical treatment, which allows carbon enrichment of the remaining austenite before final cooling. Retained austenite can transform to martensite during cold plastic deformation. This effect can be used either to strengthen the final product by the last cold forming operation, or to absorb an impact energy during the crash in the case that retained austenite remains in the final product. Modern TRIP steels are low alloyed steels with typically $0.2-0.4 \%$ of carbon and $1-2 \%$ of silicon and manganese. Various alloying concepts of TRIP steels have been researched, for example complete or partial aluminium substitution of silicon, micro-alloying by niobium, copper, phosphorus or chromium alloying [1-4].
Niobium addition to a standard C-Mn-Si steel enables TRIP microstructure to be produced even at low cooling rates and without traditional bainitic hold [5], which makes this alloying concept very promising for commercial applications. In most of the works, the processing of TRIP steels with niobium is carried out either as cold rolling followed by intercritical annealing [6], or as thermo-mechanical processing with several deformation steps [7]. For thermo-mechanical treatment, the number of deformations, deformation temperatures and sizes are very important factors influencing resulting microstructures and properties. In this work, both heat and thermo-mechanical treatments were applied to an experimental C-Mn-Si-Nb steel to evaluate the effect of processing parameters on the final microstructure and properties.

The advantage of retained austenite to an enhancement of strength and ductility of steels has been recently successfully utilized also in advanced martensitic steels processed by quenching and partitioning heat [8] or thermo-mechanical treatments $[9,10]$.

\section{Experimental program}

\subsection{Heat and thermo-mechanical processing}

Several processing strategies were tested for $\mathrm{CMnSiNb}$ steel with $0.2 \% \mathrm{C}, 1.5 \% \mathrm{Mn}, 1.8 \% \mathrm{Si}$ and $0.06 \% \mathrm{Nb}$ (wt \%). Several processing strategies, which typically produce TRIP microstructure, were designed (Table 1). To keep the processing

\footnotetext{
* REGIONAL TECHNOLOGICAL INSTITUTE, UWB IN PILSEN, UNIVERZITNI 8, 30614 PILSEN, CZECH REPUBLIC

* Corresponding author: skal@rti.zcu.cz
} 
cost efficient and environmental friendly, soaking was carried out for $100 \mathrm{~s}$ at relatively low temperature of $900^{\circ} \mathrm{C}$. Only in one case, the soaking temperature was increased to $1050^{\circ} \mathrm{C}$ to simulate typical heating conditions used in commercial rolling of low alloyed steels. For all processing methods, relatively high heating rate of $20^{\circ} \mathrm{C} / \mathrm{s}$ was used.

The first processing consisted of a two-step heat treatment without deformation. However, most of the other strategies applied various numbers of deformation steps during the cooling from the soaking temperature to the bainitic hold temperature to evaluate the effect of the number of deformation steps on the final microstructure and properties. Either one, two or three individual compressive deformations or 20 incremental deformation steps were applied to the steel during the cooling from $900^{\circ} \mathrm{C}$ to $720^{\circ} \mathrm{C}$. Individual deformations are commonly used to simulate real processing by various forming technologies, for example forging [11] or hot rolling [7]. The amount of each deformation step was equal to $10 \%$ of the actual length of the sample and all of them were compressive ones.

In the next step, a strategy with 20 incremental deformation steps was tested. This strategy simulate stress-strain states existing in materials processed by rolling mills or rotary spin extrusion with high accuracy and they enable higher total deformation to be applied to relatively small samples without the risk of cracking [12]. Each deformation step consisted of a tensile and compressive deformation. The compressive deformation was always slightly higher to achieve the change of the shape of the samples as well. The relative size of all the deformation steps was kept the same with regard to the actual size of the sample and the total logarithmic deformation was equal to 5 .

Based on the results of previous experiments, $720^{\circ} \mathrm{C}$ was kept as the temperature of the last deformation and subsequent bainitic hold was performed at $425^{\circ} \mathrm{C}$ for 600 s [13]. Average cooling rate around $14^{\circ} \mathrm{C} / \mathrm{s}$ was used for the cooling from $900^{\circ} \mathrm{C}$ to $425^{\circ} \mathrm{C}$.

Bainitic hold is a typical feature of TRIP steel processing. The last processing strategy was designed as a variant of a real rolling mill with continuous cooling and a higher soaking tem- perature of $1050^{\circ} \mathrm{C}$. Bainitic hold was in this case replaced by a change of cooling rate from $16^{\circ} \mathrm{C} / \mathrm{s}$ to $1{ }^{\circ} \mathrm{C} / \mathrm{s}$ at $425^{\circ} \mathrm{C}$. Two compressive deformations were applied at $1050^{\circ} \mathrm{C}$ and $830^{\circ} \mathrm{C}$.

Finally, a reference sample was quenched at $50^{\circ} \mathrm{C} / \mathrm{s}$ from the prevailing soaking temperature of $900^{\circ} \mathrm{C}$ down to the room temperature. The first aim of this treatment was to check ferrite occurrence at this soaking temperature. The second was to obtain mechanical properties of the steel in as-quenched conditions.

Thermo-mechanical simulator was used to process all the samples (Fig. 1). The final microstructures were analysed using Zeiss Crossbeam Auriga and EVO 25 scanning electron microscopes with an EBSD detector and light microscopy with image analysis. The volume fraction of the retained austenite was determined by X-ray diffraction phase analysis using an AXS Bruker D8 Discover automatic powder diffractometer with a HI-STAR detector and Co lamp $(\lambda K a=0.1790307 \mathrm{~nm})$. A focusing polycapillary lens was used to achieve an X-ray spot with $0.5 \mathrm{~mm}$ diameter. The measurement was carried out in the central part of the samples and spectra were taken in the range of $2 \vartheta$ from $25^{\circ}$ to $110^{\circ}$. The integrated intensities of (200) ferrite peak and (111), (002) and (022) austenite peaks were used for evaluation. In-house developed image analysis software was used to evaluate ferrite grains size by an intercept method. The mechanical properties were measured by tensile testing of flat mini-samples, with a gauge length of $5 \mathrm{~mm}$.

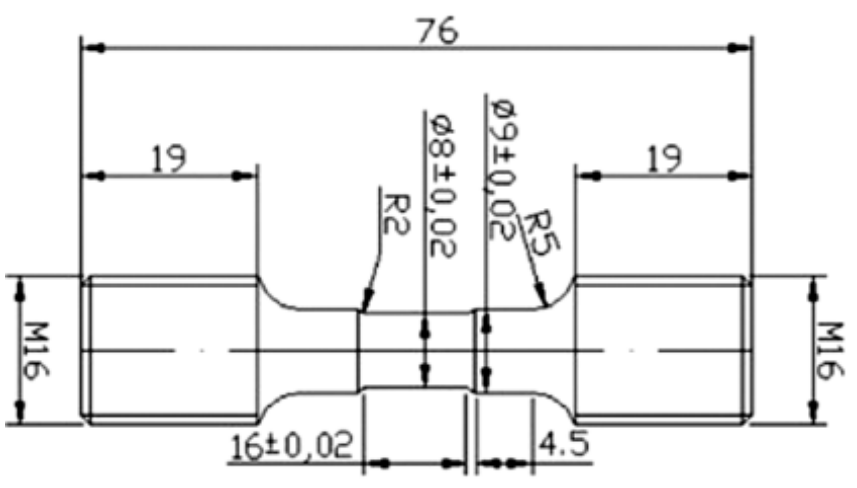

Fig. 1. Geometry of the sample for thermo-mechanical simulator

TABLE 1

Parameters of the treatment, Ferrite grain size, temperature of deformations $\left(T_{d e f}\right)$, total logarithmic deformation $(\Phi)$, yield strength $(R e)$, ultimate tensile strength $(R m)$, ductility $\left(A_{5 \mathrm{~mm}}\right)$, tensile strength and ductility product $(R m \times A)$, retained austenite volume fraction $(R A)$

\begin{tabular}{|c|c|c|c|c|c|c|c|c|}
\hline $\begin{array}{c}\text { Number of } \\
\text { deformations }\end{array}$ & $T_{d e f}\left[{ }^{\circ} \mathbf{C}\right]$ & $\Phi[-]$ & $\operatorname{Re}[\mathrm{MPa}]$ & $R m$ [MPa] & $A_{5 \mathrm{~mm}}[\%]$ & $\begin{array}{c}R m \times A \\
{[\mathrm{MPa} \%]}\end{array}$ & $R A[\%]$ & $\begin{array}{c}F \text { grain size } \\
{[\mathrm{mm}]}\end{array}$ \\
\hline \multicolumn{9}{|c|}{ Soaking at $900^{\circ} \mathrm{C} / 100 \mathrm{~s}$, cooling to $425^{\circ} \mathrm{C}$ by $14^{\circ} \mathrm{C} / \mathrm{s}$, bainitc hold at $425^{\circ} \mathrm{C} / 600 \mathrm{~s}$} \\
\hline- & - & - & 527 & 803 & 34 & 27302 & 14 & 4.8 \\
\hline 1 & $720^{\circ} \mathrm{C}$ & 0.1 & 583 & 829 & 31 & 25699 & 15 & 4.6 \\
\hline 2 & $900,720^{\circ} \mathrm{C}$ & 0.21 & 654 & 859 & 34 & 29206 & 13 & 3.1 \\
\hline 3 & $900,870,720$ & 0.31 & 603 & 810 & 33 & 26730 & 12 & 4.4 \\
\hline 20 & $900-720$ & 5 & 440 & 783 & 34 & 26622 & 12 & 4.0 \\
\hline \multicolumn{9}{|c|}{ Soaking at $1050^{\circ} \mathrm{C} / 100 \mathrm{~s}$, cooling to $425^{\circ} \mathrm{C}$ by $16^{\circ} \mathrm{C} / \mathrm{s}$, cooling to room temperature by $1{ }^{\circ} \mathrm{C} / \mathrm{s}$} \\
\hline 2 & 1050,830 & 0.21 & 403 & 978 & 30 & 29340 & 10 & 4.1 \\
\hline \multicolumn{9}{|c|}{ Reference sample: Soaking at $900^{\circ} \mathrm{C} / 100 \mathrm{~s}$, quenching to room temperature by $50^{\circ} \mathrm{C} / \mathrm{s}$} \\
\hline - & - & - & 679 & 1186 & 20 & 23720 & 4 & 3.5 \\
\hline
\end{tabular}




\section{Results and discussion}

\subsection{Microstructure and properties}

The highest average ferrite grain size was obtained after a two-step heat treatment without deformation, reaching $4.8 \mathrm{mi}-$ crometres. Bainitic blocks of a similar size as ferrite grains were found in the microstructure and the distribution of phases and structural components was very uniform (Figs. 2,3). There was $14 \%$ of retained austenite in the microstructure. The tensile strength of this microstructure was $803 \mathrm{MPa}$ and the ductility $A_{5 \mathrm{~mm}}$ reached $34 \%$.

One deformation at $720^{\circ} \mathrm{C}$ resulted in a slight refinement of ferrite grains to 4.6 micrometres, however also in an increase of bainitic blocks size in the final microstructure and generally in a higher amount of lath bainite (Fig. 4). Bainite distribution was more heterogeneous than in the microstructure after pure heat treatment. The tensile strength increased to $829 \mathrm{MPa}$ with the ductility $A_{5 \mathrm{~mm}}=31 \%$ and $15 \%$ of retained austenite.

Two deformations carried out at $900^{\circ} \mathrm{C}$ and $720^{\circ} \mathrm{C}$ refined all phases in the final microstructure (Fig. 5). The final microstructure contained bainitic areas with predominantly globular morphology, with just an occasional occurrence of larger blocks of lath bainite. These blocks were of the same size as after one deformation; however, the laths inside of them were finer. The lowest ferrite grain size around 3 micrometres was achieved in this microstructure and a volume fraction of the retained austenite was very similar to the previous two cases, reaching

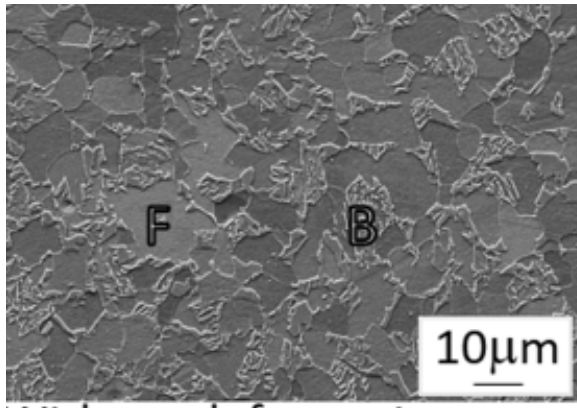

\section{Without deformation}

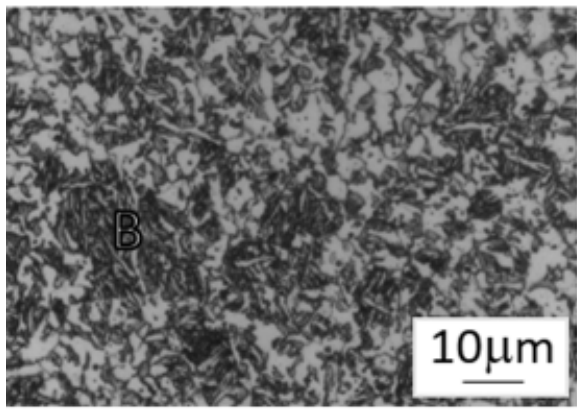

Continuous cooling

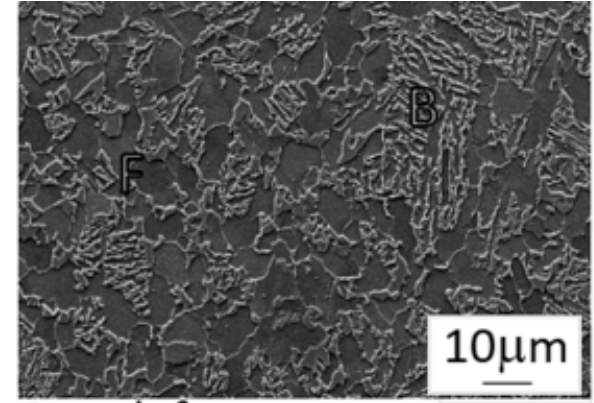

One deformation

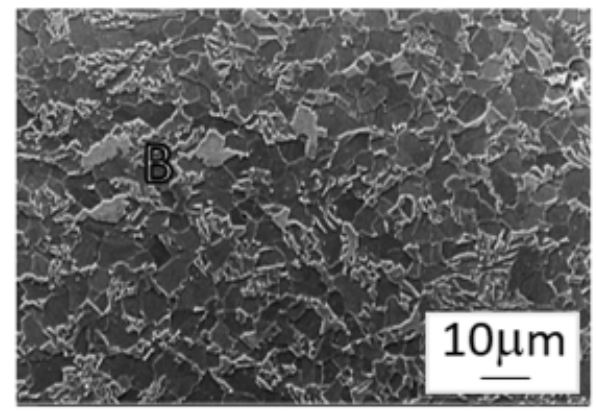

Twenty deformations

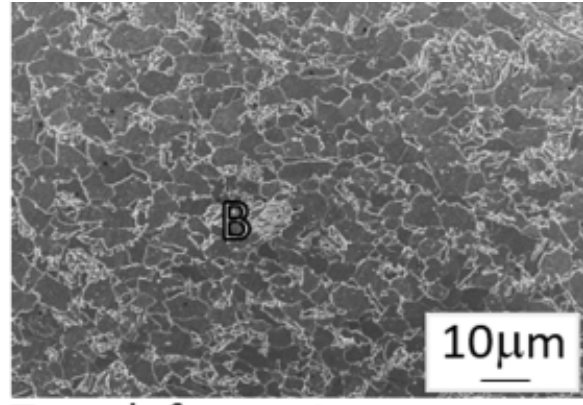

\section{Two deformations}

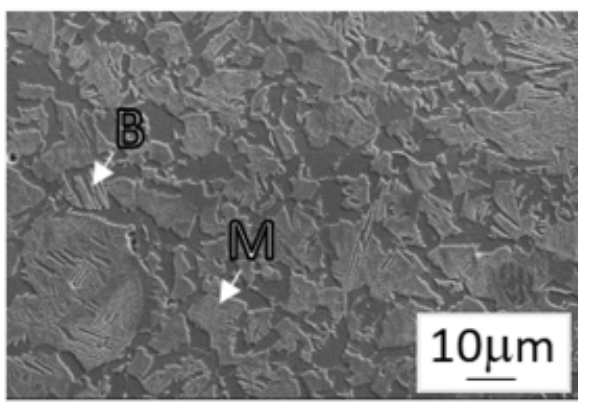

Quenched at $50^{\circ} \mathrm{C} / \mathrm{s}$

Fig. 2. Microstructure overview after various heat and thermo-mechanical treatments

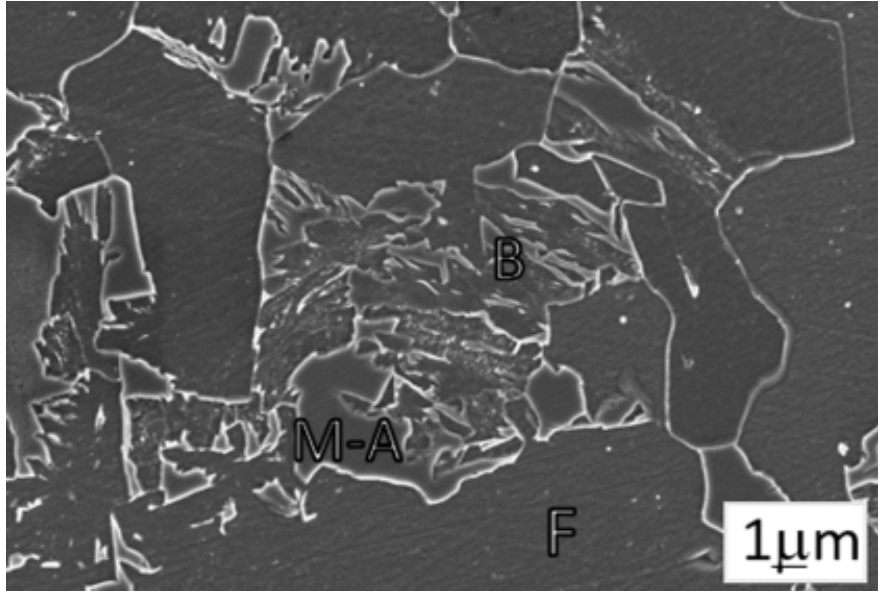

Fig. 3. Heat treatment without deformation, $900^{\circ} \mathrm{C} / 100 \mathrm{~s}$, cooling at $14^{\circ} \mathrm{C} / \mathrm{s}$ to $425^{\circ} \mathrm{C} / 600 \mathrm{~s}$, coarse blocks of globular bainite, ferrite grains

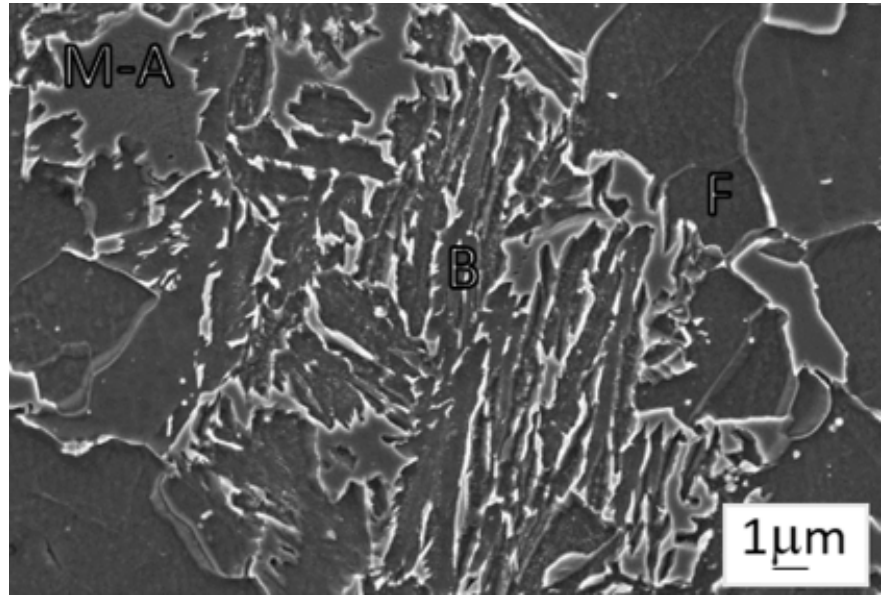

Fig. 4. Processing with $900^{\circ} \mathrm{C} / 100$ s soaking, one deformation at $720^{\circ} \mathrm{C}$, cooling at $14^{\circ} \mathrm{C} / \mathrm{s}$ to $425^{\circ} \mathrm{C} / 600 \mathrm{~s}$, coarse blocks of lath bainite in the microstructure 


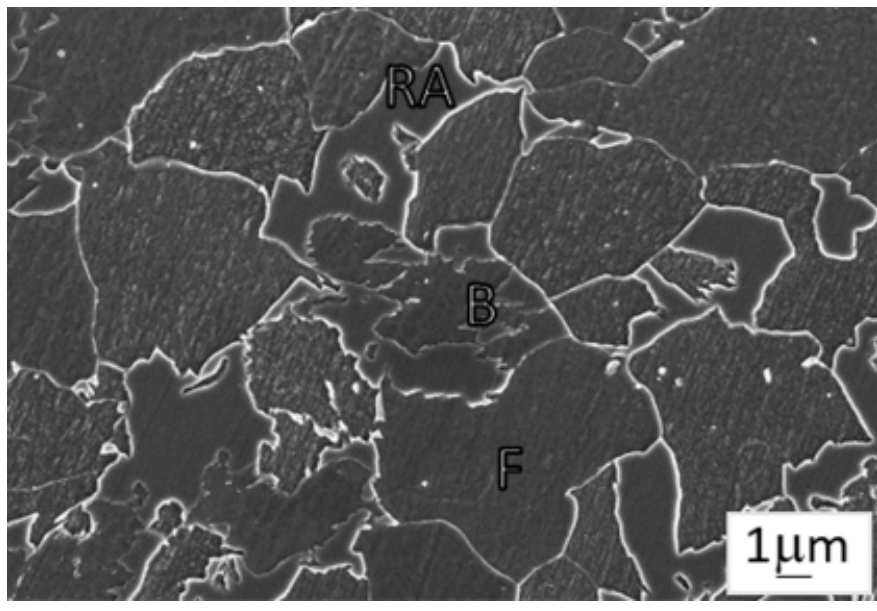

Fig. 5. Processing with $900^{\circ} \mathrm{C} / 100$ s soaking, two deformations at $900^{\circ} \mathrm{C}$ and $720^{\circ} \mathrm{C}$, cooling at $14^{\circ} \mathrm{C} / \mathrm{s}$ to $425^{\circ} \mathrm{C} / 600 \mathrm{~s}$, fine microstructure with globular bainite

$13 \%$. Ferrite refinement was therefore most probably responsible for another increase of the strength to $859 \mathrm{MPa}$ combined with a high ductility $A_{5 \mathrm{~mm}}$ of $34 \%$.

Higher number of deformations resulted in a drop of tensile strength, even though the volume fraction of the retained austenite was still relatively high, reaching $12 \%$. Three deformations applied at $900^{\circ} \mathrm{C}, 870^{\circ} \mathrm{C}$ and $720^{\circ} \mathrm{C}$ produced the microstructure with the tensile strength of $810 \mathrm{MPa}$ and the ductility $A_{5 \mathrm{~mm}}=33 \%$.

Twenty incremental deformation steps with a decreasing size of an applied deformation created more homogeneous distribution of the finer areas of lath bainite (Figs. 2,6). However, large complex laths of M-A constituent and bulk islands of M-A constituent with prevailing martensitic microstructure and retained austenite being only at the very edges, were also typical for this microstructure. There were still $12 \%$ of the retained austenite. This microstructure possessed a lower strength of only $783 \mathrm{MPa}$ with the ductility $A_{5 \mathrm{~mm}}=34 \%$. The lowest strength obtained by this processing was most probably caused by coarsening of M-A constituents, which could also influence the stability of the comprised retained austenite.

The effect of various numbers of deformation steps on texture of the final microstructures was not considered in this work. It was already demonstrated by Jirkova [14] for the same steel with $0.03 \%$ of niobium, that there was hardly any difference between the textures in ferrite and austenite obtained after thermo-mechanical treatment with $900^{\circ} \mathrm{C}$ soaking temperature and various numbers of deformation steps applied during the cooling from $900^{\circ} \mathrm{C}$ to $720^{\circ} \mathrm{C}$. Based on the X-ray diffraction analysis, the same weak preferred orientation of $<110>$ in ferrite and $<200>$ in austenite were found in the microstructures after several treatments with the same thermal schedules and up to 20 deformation steps applied in the same temperature interval.

Thermo-mechanical processing of TRIP steels is typically done with a hold in a bainite transformation region. However, it has been demonstrated particularly for $\mathrm{Nb}$ alloyed steel that suitable microstructures with a sufficient volume fraction of retained austenite can be achieved also by the processing with continuous cooling. In a previous work, incremental deformation steps combined with a very slow cooling at a constant rate of $1^{\circ} \mathrm{C} / \mathrm{s}$ were successfully utilized for the same $\mathrm{CMnSiNb}$ TRIP steel [5]. In recent work, two individual deformations were applied at the temperatures of $1050^{\circ} \mathrm{C}$ and $830^{\circ} \mathrm{C}$ and the cooling rate was changed at $425^{\circ} \mathrm{C}$ to allow quicker cooling at higher temperatures. The final microstructure consisted of a mixture of free ferrite, bainite and M-A constituent and the morphology was very similar as in the previous samples with bainitic hold (Fig. 7). Martensitic or M-A constituent laths or islands formed the edges of continuously cooled bainitic areas, showing a lower stability of the remaining austenite during the final cooling stage. Even a lower cooling rate of $1{ }^{\circ} \mathrm{C} / \mathrm{s}$ used for the cooling from $425^{\circ} \mathrm{C}$ to room temperature, did not offer enough time for partitioning of a sufficient carbon content into the remaining austenite to make it stable against martensitic transformation. However, there was still $10 \%$ of retained austenite detected by an X-ray diffraction and this microstructure possessed one of the best combinations of the mechanical properties of all the tested samples. It reached the highest strength of $978 \mathrm{MPa}$ with a very good ductility $\mathrm{A}_{5 \mathrm{~mm}}=30 \%$. In comparison, the microstructure after continuous cooling at a constant cooling rate of $1^{\circ} \mathrm{C} / \mathrm{s}$ and 20 incremental deformation steps reached only the strength of $850 \mathrm{MPa}$ with the ductility $\mathrm{A}_{5 \mathrm{~mm}}=24 \%$ [5].

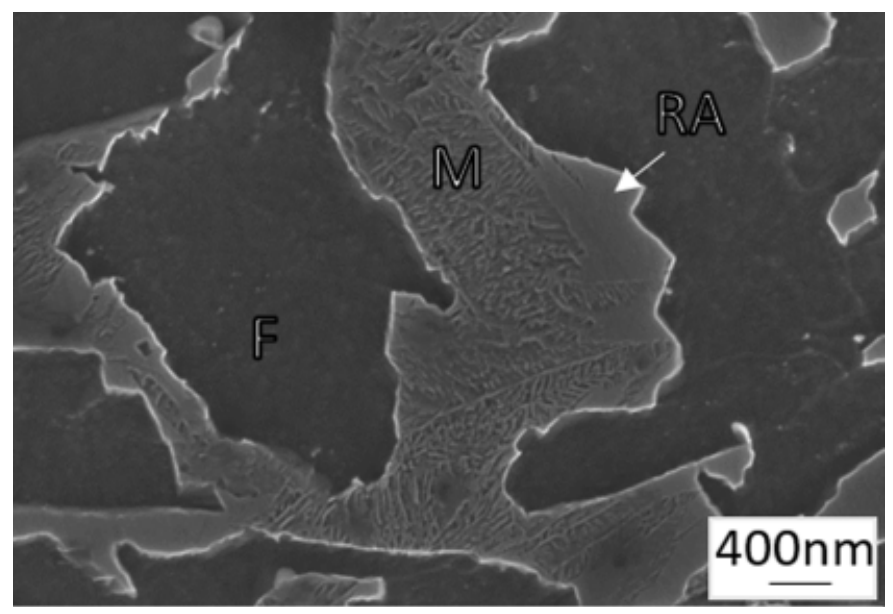

Fig. 6. Processing with $900^{\circ} \mathrm{C} / 100$ s soaking, 20 incremental deformation steps at $900-720^{\circ} \mathrm{C}$, cooling at $14^{\circ} \mathrm{C} / \mathrm{s}$ to $425^{\circ} \mathrm{C} / 600 \mathrm{~s}$, M-A constituent with complex shape

Direct cooling from $900^{\circ} \mathrm{C}$ to room temperature at $50^{\circ} \mathrm{C} / \mathrm{s}$ produced a mixed martensitic-bainitic microstructure with chains of proeutectoid ferrite at the prior austenite boundaries (Fig. 8). Around $20 \%$ of free ferrite were found in the microstructure by an image analysis. This microstructure reached the highest strength of $1186 \mathrm{MPa}$ due to a large martensite volume fraction, however it was combined with the lowest ductility of $20 \%$ resulting from the lowest amount of retained austenite (4\%) and ferrite. The reference sample demonstrated a relatively high 


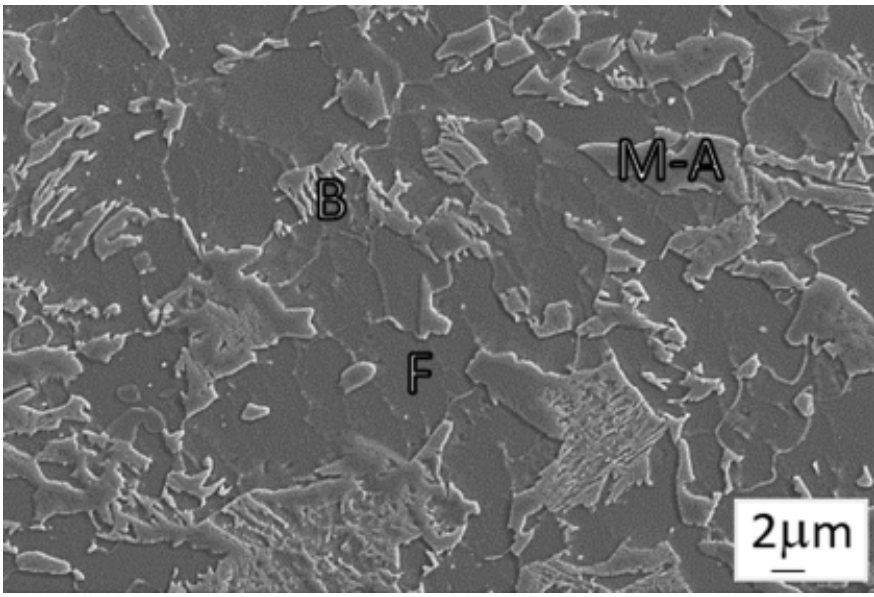

Fig. 7. Processing with continuous cooling from $1050^{\circ} \mathrm{C}$ with 2 deformations at $1050^{\circ} \mathrm{C}$ and $830^{\circ} \mathrm{C}$, cooling rate $16^{\circ} \mathrm{C} / \mathrm{s}$ to $425^{\circ} \mathrm{C}$ and $1{ }^{\circ} \mathrm{C} / \mathrm{s}$ to room temperature, bainitic blocks with large M-A constituent at the edges

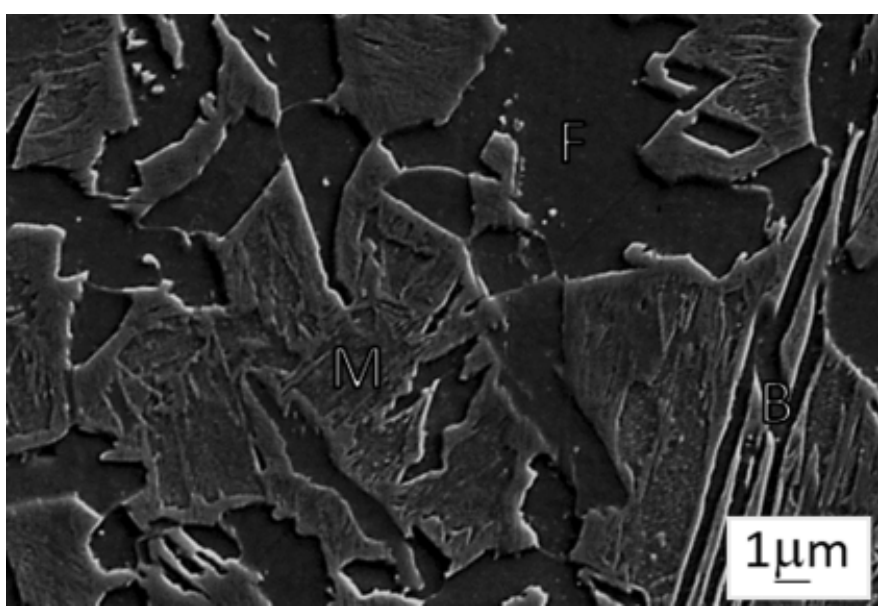

Fig. 8. Water quenching from $900^{\circ} \mathrm{C} / 100$ s soaking at $50^{\circ} \mathrm{C} / \mathrm{s}$, large bainitic and martensitic blocks surrounded by ferrite grains

ductility of this steel even after a conventional quenching from an intercritical region. However, the stabilization of around $10 \%$ of retained austenite and exchange of most of the martensite for bainite improved the ductility by $50 \%$, as its gradual transformation to martensite during tensile test postpones the onset of necking, thus prolonging the area of homogeneous plastic deformation.

\subsection{Effect of niobium}

It has been long known that the effect of niobium on the final microstructure and mechanical properties depends on its state [15-18]. Niobium can be present in a steel either dissolved in a solid solution or precipitated in niobium carbides $(\mathrm{NbC})$ or more complex niobium carbo-nitrides $(\mathrm{Nb}(\mathrm{C}, \mathrm{N}))$. The ratio of dissolved and precipitated niobium is mainly determined by soaking conditions, namely by a heating rate, soaking temperature and soaking hold. During thermo-mechanical treatment, dissolved niobium can participate in strain induced precipitation, which can have significant effect on recrystallization processes in the steel and subsequent phase transformations. A soaking temperature of at least $1200^{\circ} \mathrm{C}$ is generally required to dissolve a major fraction of primary $\mathrm{NbC}$ in low alloyed $\mathrm{C}-\mathrm{Mn}-\mathrm{Si}-\mathrm{Nb}$ steels [17]. Relatively low heating temperature of $900^{\circ} \mathrm{C}$ with $100 \mathrm{~s}$ hold combined with a higher heating rate of $20^{\circ} \mathrm{C} / \mathrm{s}$ would keep $\mathrm{Nb}$ diffusivity and $\mathrm{Nb}$ content in solid solution low for most of the processing methods used in this work. Hong et al. [17] reported that $94 \%$ of niobium carbides was still undissolved after $2 \mathrm{~min}$ hold at $900^{\circ} \mathrm{C}$ and no change in $\mathrm{NbC}$ state was found after 60 s hold at this soaking temperature by Hausmann et al. [18]. It can be therefore assumed that the amount, size and morphology of $\mathrm{NbC}$ precipitates did not play significant role in variations of the final microstructures and mechanical properties obtained for the samples soaked at $900^{\circ} \mathrm{C}$, as the precipitates remained in all samples in their original pre-processing state.

However, partial $\mathrm{NbC}$ dissolution could have occurred at a soaking temperature of $1050^{\circ} \mathrm{C}$, where around $10 \%$ of primary niobium carbides could be dissolved according to [17]. This treatment with continuous cooling resulted in the highest strength of $972 \mathrm{MPa}$. It should be also noted that a similar treatment with the same soaking conditions and deformation temperature interval, but with slower cooling rate of $1{ }^{\circ} \mathrm{C} / \mathrm{s}$, produced in previous work markedly lower strength and ductility [5]. High strength obtained in this work for the sample soaked at $1050^{\circ} \mathrm{C}$ should therefore not be seen primarily as a result of partial $\mathrm{NbC}$ dissolution at a higher soaking temperature and possible strain induced precipitation during the following deformations. Good combination of mechanical properties should be in this case attributed rather to the synergic effect of a more complex final microstructure with bainitic areas strengthened by adjacent M-A constituent islands distributed homogenously in a soft ferritic matrix.

\subsection{EBSD}

As the volume fraction of the retained austenite was nearly the same for all the processing, EBSD analysis was performed at two samples with the most different treatments. The first one was after the heat treatment without deformation (Fig. 9) and the second one after thermo-mechanical processing with 20 deformation steps (Fig. 10). In both microstructures, retained austenite was detected in the form of the bainitic laths and fine bulk islands. Inverse pole figures were calculated for both samples in all three directions $\mathrm{x}, \mathrm{y}$ and $\mathrm{z}$. For both samples, retained austenite laths in neighbouring bainitic blocks had the same orientation, which happened also to be similar to the orientation of surrounding grains of proeutectoid ferrite. It is interesting to note that the orientation of bainitic ferrite laths is quite different. Bulk islands of retained austenite lining the boundary of free ferrite grain (Fig. 9) had different orientation from austenitic laths of nearest bainitic areas. 

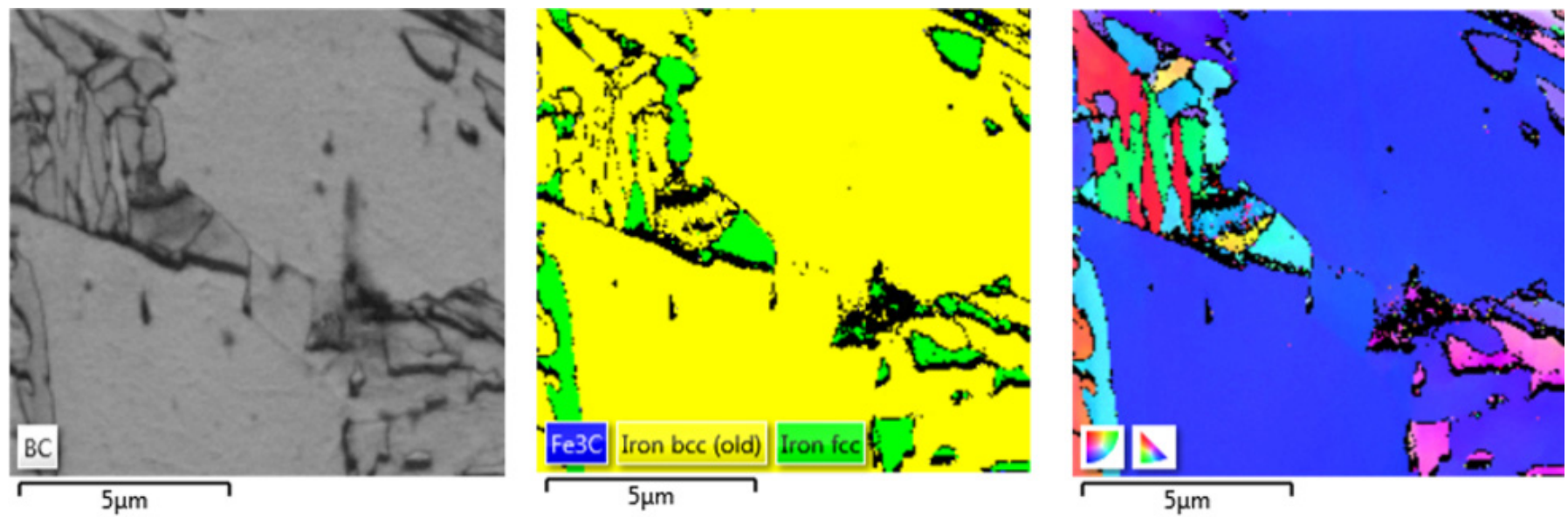

Fig. 9. Heat treatment: Band contrast, phase map, IPF Z map, several different orientations of retained austenite, the laths within the same bainitic block had the same orientation
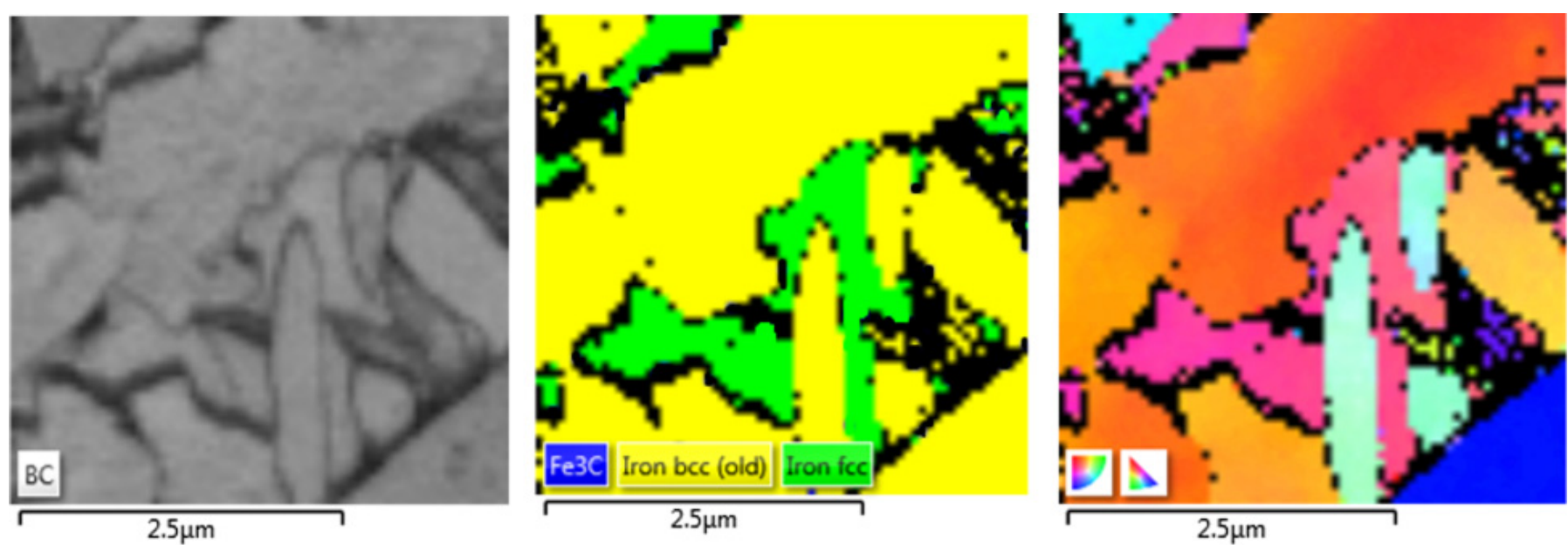

Fig. 10. Processing with 20 deformation steps: Band contrast, phase map, IPF Z map - areas marked as retained austenite had the same orientation

\section{Conclusions}

High versatility of niobium alloyed high strength steel was demonstrated in this work. The steel possessed good strength of $1186 \mathrm{MPa}$ and ductility $A_{5 \mathrm{~mm}}=20 \%$ even after simple quenching from an intercritical region. These properties were however further improved by dedicated heat and thermo-mechanical treatments.

Two step heat treatment, or thermo-mechanical processing with either several individual deformations, or with a set of 20 incremental deformation steps can be carried out on C-Mn$\mathrm{Si}-\mathrm{Nb}$ steel to produce TRIP microstructure with the strength around $850 \mathrm{MPa}$ and the ductility over $30 \%$. The microstructure with $10 \%-14 \%$ of retained austenite can be obtained even after thermo-mechanical processing with continuous cooling and by heat treatment alone, without any deformation. Due to the low sensitivity of final mechanical properties to the change of processing parameters, this steel has high potential for a wide range of commercial applications.

The best combinations of strength and ductility, accompanied by high energy absorption during deformation, expressed by strength and ductility products $(R m \times A)$ around $30000 \mathrm{MPa} \%$, were obtained for two different thermo-mechanical processing. The first one was carried out with $900^{\circ} \mathrm{C}$ soaking temperature and two deformations during the cooling to a bainitic hold, while the second processing used $1050^{\circ} \mathrm{C}$ soaking temperature followed also by two deformations but with continuous cooling schedule. Continuous cooling resulted in the highest strength of nearly $980 \mathrm{MPa}$ with very good ductility of $30 \%$, while the processing with bainitic hold possessed higher ductility of $34 \%$ with tensile strength of $859 \mathrm{MPa}$.

\section{Acknowledgement}

The present contribution has been prepared under project LO1502 'Development of the Regional Technological Institute' under the auspices of the National Sustainability Programme I of the Ministry of Education of the Czech Republic aimed to support research, experimental development and innovation. 


\section{REFERENCES}

[1] Qingxiao Feng et al., Mat. Sci. And Eng. A 605, 14-21 (2014).

[2] J. Chiang et al., Mat. Sci. And Eng. A 638, 132-142 (2015).

[3] L. Kucerova, H. Jirkova, B. Masek, Archives of Metallurgy and Materials 59 (3), 1189-1192 (2014).

[4] E.V. Pereloma, I.B. Timokhina, P.D. Hodgson, Materials Science and Engineering A 273-275, 448-452 (1999).

[5] L. Kučerová, H. Jirková, B. Mašek, Materials Today: Proceedings 2 (3), 677-680, (2014).

[6] P.J. Jacques et al., ISIJ Int 41, 1068-1074 (2001).

[7] A. Grajcar, P. Skrzypczyk, D. Woźniak, Archives of Metallurgy and Materials 59 (4), 1691-1697 (2014).

[8] L. Kucerova et al., in: Annals of DAAAM and Proceedings of the International DAAAM Symposium. Vienna; Austria, 2009, 1035-1036.

[9] D. Hauserova et al., Procedia Engineering 10, 2961-2966 (2011).

[10] B. Mašek et al., Journal of Iron and Steel Research International 18, 730-734 (2011).
[11] J. Zrnik et al., Journal of Materials Processing Technology, 367372 (2007).

[12] B. Masek et al., Mechanical Behavior of Materials X 345-346, 943-946 (2007).

[13] B. Masek et al.,in: Metal 2010: 19th International Metallurgical and Materials Conference. 203-208,_Brno, Czech Republic 2010.

[14] H. Staňková, Einfluss der inkrementellen Deformationen bei der thermomechanischen Behandlung auf die Eigenschaften von TRIP-Stählen, Dissertation, 2008, Eigenverlag, Chemnitz, ISSN 1860-4773.

[15] D. Krizan, B.C. De Cooman, Steel Res. Int. 79, 513-522 (2008).

[16] A. Grajcar, Journal of Thermal Analysis and Calorimetry 118/2, 1011-1020 (2014).

[17] S.C. Hong et al., Materials Science and Engineering A355, 241248 (2003).

[18] K. Hausmann et al., Material Science and Engineering A588, $142-150$ (2013). 